\title{
Strategies for effective dissemination of research to United States policymakers: a systematic review
}

\author{
Laura Ellen Ashcraft ${ }^{1 *}$ D, Deirdre A. Quinn ${ }^{2}$ and Ross C. Brownson ${ }^{3,4}$
}

\begin{abstract}
Background: Research has the potential to influence US social policy; however, existing research in this area lacks a coherent message. The Model for Dissemination of Research provides a framework through which to synthesize lessons learned from research to date on the process of translating research to US policymakers.

Methods: The peer-reviewed and grey literature was systematically reviewed to understand common strategies for disseminating social policy research to policymakers in the United States. We searched Academic Search Premier, PolicyFile, SocINDEX, Social Work Abstracts, and Web of Science from January 1980 through December 2019. Articles were independently reviewed and thematically analyzed by two investigators and organized using the Model for Dissemination of Research.

Results: The search resulted in 5225 titles and abstracts for inclusion consideration. 303 full-text articles were reviewed with 27 meeting inclusion criteria. Common sources of research dissemination included government, academic researchers, the peer reviewed literature, and independent organizations. The most frequently disseminated research topics were health-related, and legislators and executive branch administrators were the most common target audience. Print materials and personal communication were the most common channels for disseminating research to policymakers. There was variation in dissemination channels by level of government (e.g., a more formal legislative process at the federal level compared with other levesl). Findings from this work suggest that dissemination is most effective when it starts early, galvanizes support, uses champions and brokers, considers contextual factors, is timely, relevant, and accessible, and knows the players and process.
\end{abstract}

Conclusions: Effective dissemination of research to US policymakers exists; yet, rigorous quantitative evaluation is rare. A number of cross-cutting strategies appear to enhance the translation of research evidence into policy.

Registration: Not registered.

Keywords: Systematic review, Dissemination, Dissemination science, Social policy, Public policy

\footnotetext{
* Correspondence: lauraellenashcraft@pitt.edu

'University of Pittsburgh School of Social Work, 2117 Cathedral of Learning,

4200 Fifth Avenue, Pittsburgh, PA 15260, USA

Full list of author information is available at the end of the article
}

(C) The Author(s). 2020 Open Access This article is licensed under a Creative Commons Attribution 4.0 International License, which permits use, sharing, adaptation, distribution and reproduction in any medium or format, as long as you give appropriate credit to the original author(s) and the source, provide a link to the Creative Commons licence, and indicate if changes were made. The images or other third party material in this article are included in the article's Creative Commons licence, unless indicated otherwise in a credit line to the material. If material is not included in the article's Creative Commons licence and your intended use is not permitted by statutory regulation or exceeds the permitted use, you will need to obtain permission directly from the copyright holder. To view a copy of this licence, visit http://creativecommons.org/licenses/by/4.0/. The Creative Commons Public Domain Dedication waiver (http://creativecommons.org/publicdomain/zero/1.0/) applies to the data made available in this article, unless otherwise stated in a credit line to the data. 


\section{Contributions to the literature}

- This is one of the first systematic reviews to synthesize how social policy research evidence is disseminated to US policymakers.

- Print materials and personal communications were the most commonly used channels to disseminate social policy research to policymakers.

- Several cross-cutting strategies (e.g., start early, use evidence "champions," make research products more timely, relevant, and accessible) were identified that are likely to lead to more effective translate of research evidence into the policy making process in the United States.

\section{Background}

In recent years, social scientists have sought to understand how research may influence policy $[1,2]$. Interest in this area of investigation has grown with the increased availability of funding for policy-specific research (e.g., dissemination and implementation research) [3]. However, because of variation in the content of public policy, this emerging area of scholarship lacks a coherent message that specifically addresses social policy in the United States (US). While other studies have examined the use of evidence in policymaking globally [4-7], the current review focuses on US social policy; for the purposes of this study, social policy includes policies which focus on antipoverty, economic security, health, education, and social services [8-10].

Significant international research exists on barriers and facilitators to the dissemination and use of research evidence by policymakers $[4,5]$. Common themes include the importance of personal relationships, the timeliness of evidence, and resource availability [4, 5]. Previous work demonstrates the importance of understanding policymakers' perceptions and how evidence is disseminated. The current review builds on this existing knowledge to examine how research evidence reaches policymakers and to understand what strategies are likely to be effective in overcoming identified barriers.

Theoretical frameworks offer a necessary foundation to identify and assess strategies for disseminating research to policymakers. The Model for Dissemination of Research integrates Diffusion of Innovations Theory and Social Marketing Theory with the Mathematical Theory of Communication [11, 12] and the Matrix of Persuasive Communication $[13,14]$ to address the translation gap between research and policy. The purpose of the Model for Dissemination of Research is to highlight the gaps between research and targets audiences (e.g., policymakers) and improve dissemination through the use of a theoretical foundation and review of the literature [15].
Diffusion of Innovations Theory describes the spread and adoption of novel interventions through an "s-curve," ordered process, and characteristics of the message and audience [16]. Additional theoretical contributions for dissemination research come from Social Marketing Theory, which postulates commercial marketing strategies summarized by the four P's (produce, price, place, and promotion) and the understanding that communication of the message alone will not change behavior [17].

The Model for Dissemination of Research includes the four key components described by Shannon and Weaver $[11,12]$ and later McGuire $[13,14]$ of the research translation process: the source, message, audience, and channel (Fig. 1). The source includes researchers who generate evidence. The message includes relevant information sent by the source on a policy topic. The audience includes those receiving the message via the channel [15]. The channel is how the message gets from the source to the audience [15].

While the Model for Dissemination of Research and its origins (i.e., the Mathematical Theory of Communication and Diffusion of Innovations Theory) appear linear in their presentation, Shannon and Weaver $[11,12]$ and Rogers [16] clearly acknowledge that the dissemination of information is not a linear process and is effected by the environment within which it occurs. This approach aligns with the system model or knowledge to action approach proposed by Best and Holmes [18]. The systems model accounts for influence of the environment on a process and accounts for the complexity of the system [18]. Therefore, while some theoretical depictions appear linear in their presentation; it is important to acknowledge the critical role of systems thinking.

To date, lessons learned from dissemination and implementation science about the ways in which research influences policy are scattered across diverse disciplines and bodies of literature. These disparate lessons highlight the critical need to integrate knowledge across disciplines. The current study aims to make sense of and

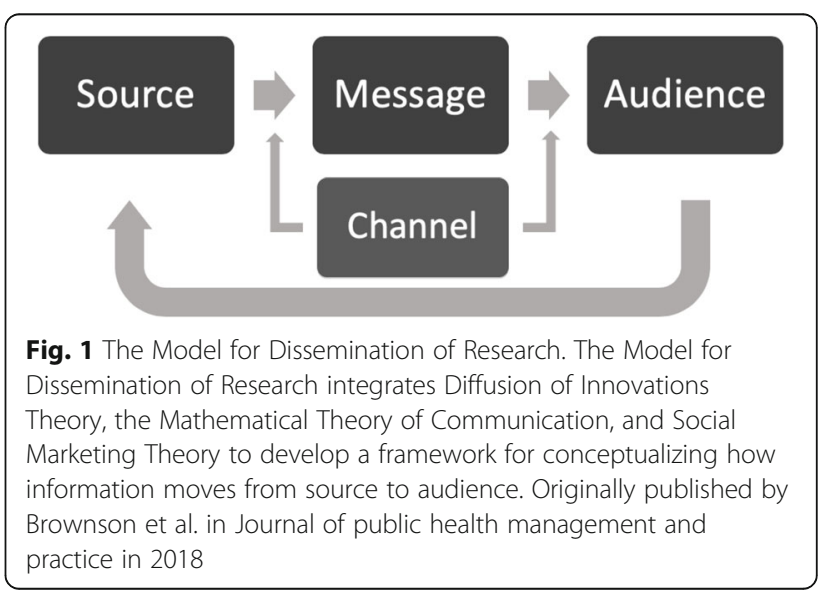


distill these lessons by conducting a systematic review of scientific literature on the role of research in shaping social policy in the United States. The results of this systematic review are synthesized in a preliminary conceptual model (organized around the Model for Dissemination of Research) with the goal of improving dissemination strategies for the translation of scientific research to policymakers and guiding future research in this area.

This systematic review aims to synthesize existing evidence about how research has been used to influence social policy and is guided by the following research questions:

1. What are common strategies for using research to influence social policy in the United States?

2. What is the effectiveness of these strategies?

\section{Methods}

We used the Preferred Reporting Items for Systematic Reviews and Meta-Analyses (PRISMA-P) model [19, 20] to examine and distill existing studies on strategies for using research evidence to influence social policy.

\section{Eligibility criteria}

Studies were eligible for this review if they met the following inclusion criteria: (1) occurred in the United States; (2) reported in English; (3) systematically evaluated the impact of research on social policy (this typically excluded studies focusing on policymaker dissemination preferences); (4) discussed domestic social policy (as defined above); and (5) were published in the peer reviewed literature or the grey literature (e.g., think tank research briefs, foundation research publications).

We chose to focus our review on the United States to capture the strengths and challenges of its unique, multi-level policy and political environment. The decentralized structure of government in the United States allows significant decision-making authority at the state and local levels, with wide variation in capacity and the availability of resources across the country [21]. For example, some states have full-time legislatures while other states have part-time legislatures. In total, these factors create a fitting and complex environment to examine the dissemination of research to policymakers. The influence of lobbying in the United States also differs from other western countries. In the United States, there is more likely to be a "winner-take-all" process where some advocates (often corporations and trade associations) have disproportionate influence [22]. In addition, the role of evidence differs in the US compared with other countries, where the US tends to take a narrower focus on intervention impact with less emphasis on systemlevel issues (e.g., implementation, cost) [23].
Studies were excluded if they were not in English or occurred outside of the United States. We also excluded non-research sources, such as editorials, opinion pieces, and narrative stories that contain descriptions of dissemination strategies without systematic evaluation. Further, studies were excluded if the results focused on practitioners (e.g., case managers, local health department workers) and/or if results for practitioners could not be parsed from results for policymakers.

To identify studies that systematically evaluated the impact of research on social policy, we reviewed the research questions and results of each study to determine whether or not they examined how research evidence reaches policymakers (as opposed to policymaker preferences for disseminated research). For example, we would not include a research study that only describes different types of policy briefs, without also evaluating how the briefs are used by policymakers to inform policy decisions. We used the Model for Dissemination of Research, as defined above, to see if and how the studies describe and test the channels of dissemination. We built on the Model of Dissemination by also considering passive forms of knowledge, such as peer-reviewed literature or research briefs, as potential sources of knowledge and not just as channels in and of themselves.

\section{Information sources}

We took a three-pronged approach to develop a comprehensive understanding of existing knowledge in this area. First, we searched the peer reviewed literature using the following databases: Academic Search Premier, PolicyFile, SocINDEX, Social Work Abstracts, and Web of Science. We expanded the inquiry for evidence by searching the grey literature through PolicyFile, and included recommendations from experts in the field of dissemination of research evidence to policymakers resulting in 137 recommended publications.

\section{Search strategy}

Our search strategy included the following terms: [research OR study OR studies OR knowledge] AND [policy OR policies OR law OR laws OR legislation] AND [use OR utilization OR utilisation] OR [disseminate OR dissemination OR disseminating] OR [implementation OR implementing OR implement] OR [translate OR translation OR translating]. Our search was limited to studies in the United States between 1980 and 2019. We selected this timeframe based on historical context: the 1950 s through the 1970s saw the development of the modern welfare state, which was (relatively) complete by 1980. However, shifting political agendas in the 1980s saw the demand for evidence increase to provide support for social programs [24]; we hoped to capture this increase in evidence use in policy. 


\section{Selection process}

All titles and abstracts were screened by the principal investigator (LEA) with $20 \%$ reviewed at random by a coinvestigator (DAQ) with total agreement post-training. Studies remaining after abstract screening moved to full text review. The full text of each study was considered for inclusion (LEA and DAQ) with conflicts resolved by consensus. The data abstraction form was developed by the principal investigator (LEA) based on previous research $[25,26]$ and with feedback from co-authors. Data were independently abstracted from each reference in duplicate with conflicts resolved by consensus (LEA and DAQ). We completed reliability checks on $20 \%$ of the final studies, selected at random, to ensure accurate data abstraction.

\section{Data synthesis}

Abstracted data was qualitatively analyzed using thematic analysis (LEA and DAQ) and guided by the Model for Dissemination of Research. The goal of the preliminary conceptual model was to synthesize components of dissemination for studies that evaluate the dissemination of social policy to policymakers.

\section{Results \\ Descriptive results}

The search of the literature resulted in 5675 articles and 137 articles recommended by content experts for review with 5225 titles and abstracts screened after duplicates removed. Of those articles, 4922 were excluded due to not meeting inclusion criteria. Further, 303 full text articles were reviewed with 276 excluded as they did not meet inclusion criteria. Twenty-seven articles met inclusion criteria (see the Fig. 2 for the PRISMA flow diagram).

Included studies are listed in Table 1 . The 27 included 6 studies using quantitative methods, 18 that employed qualitative methods, and 3 that used a mixed methods approach. The qualitative studies mostly employed interviews $(n=10)$, while others used case studies $(n=6)$ or focus groups $(n=3)$. Most studies examined state-level policy $(n=18)$ and nine studies examined federal-level policy, with some studies looking at multiple levels of

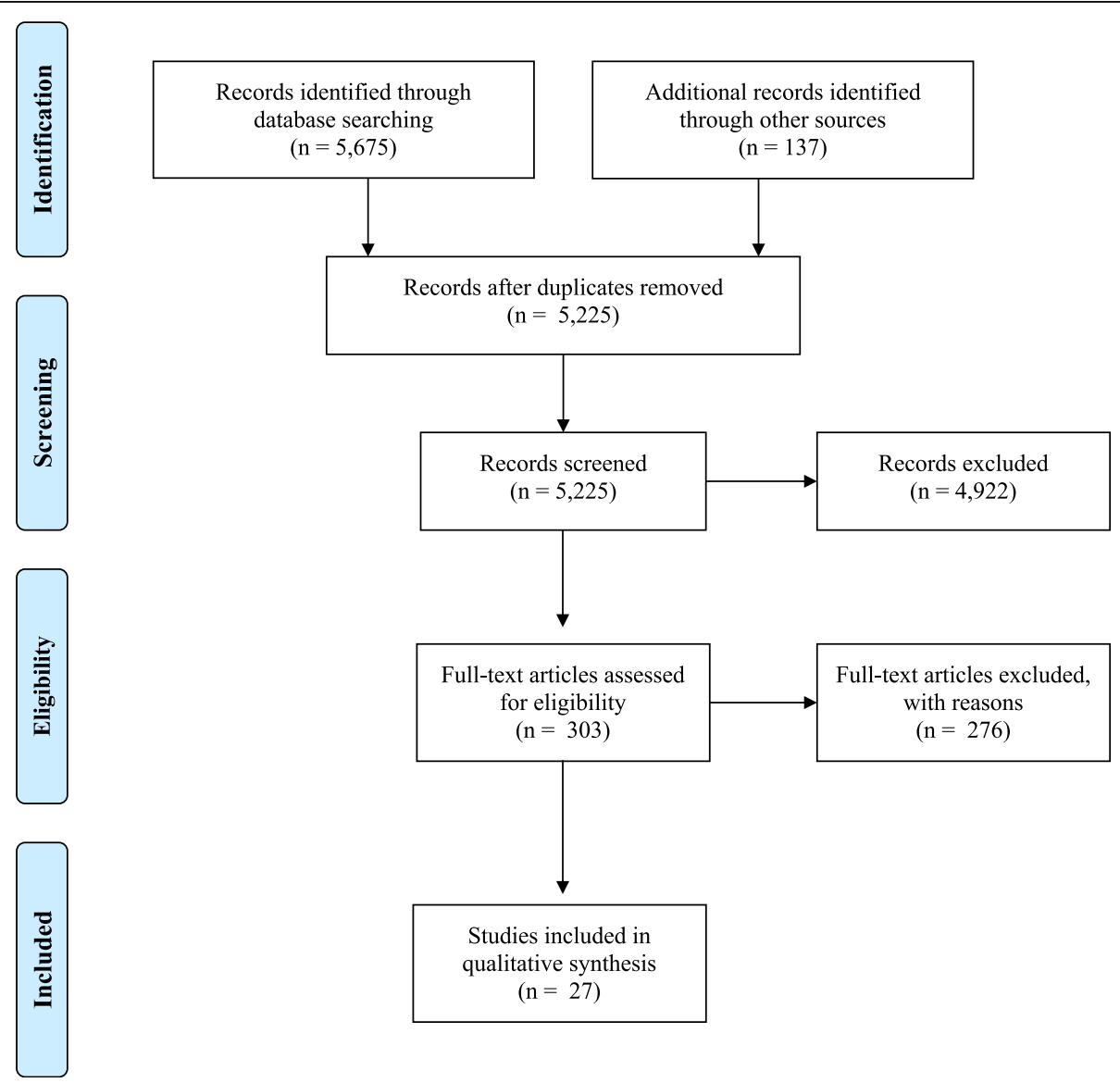

Fig. 2 PRISMA flowchart. The preferred reporting items for systematic reviews and meta-analyses (PRISMA) flow diagram reports included and excluded articles in the systematic review 


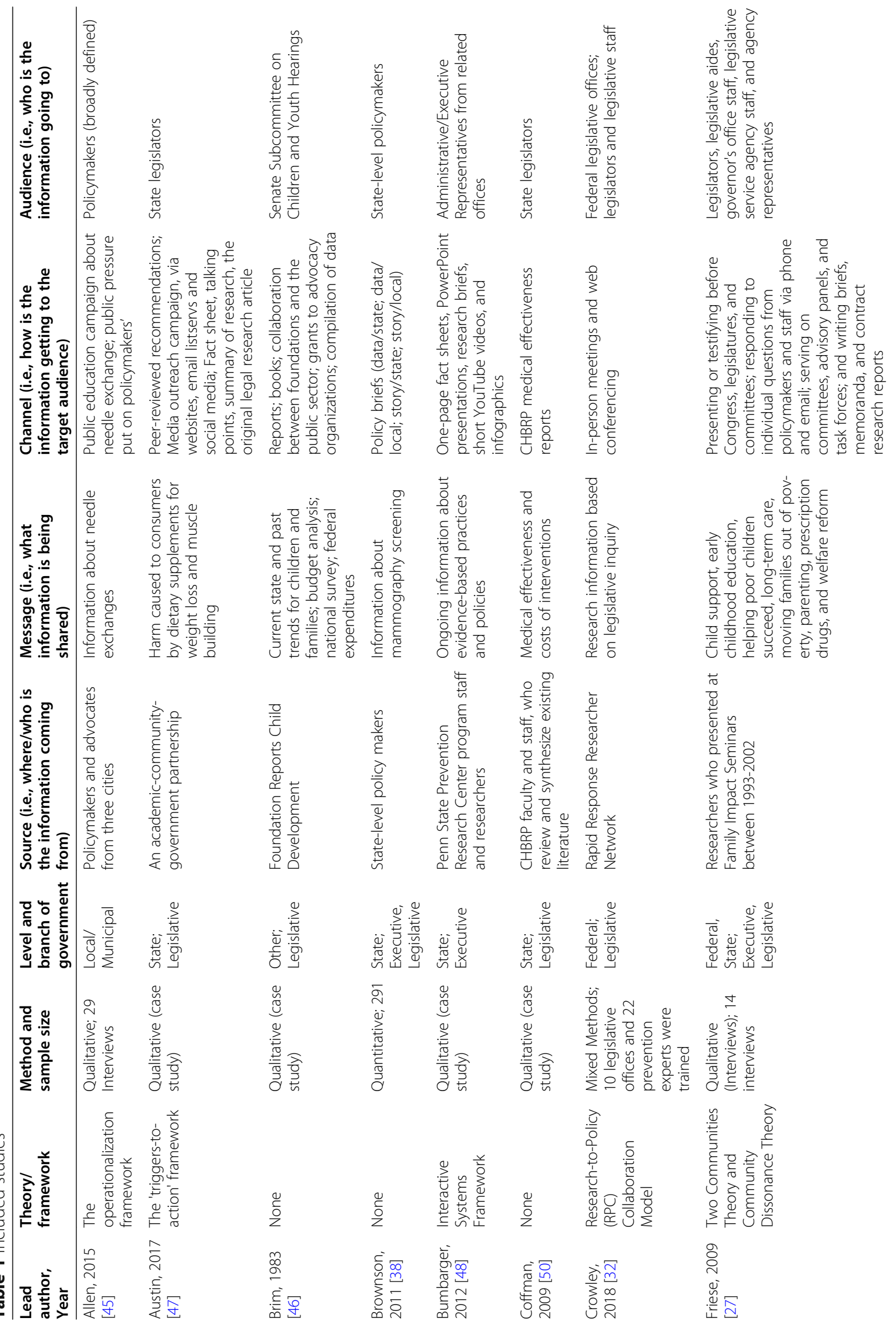




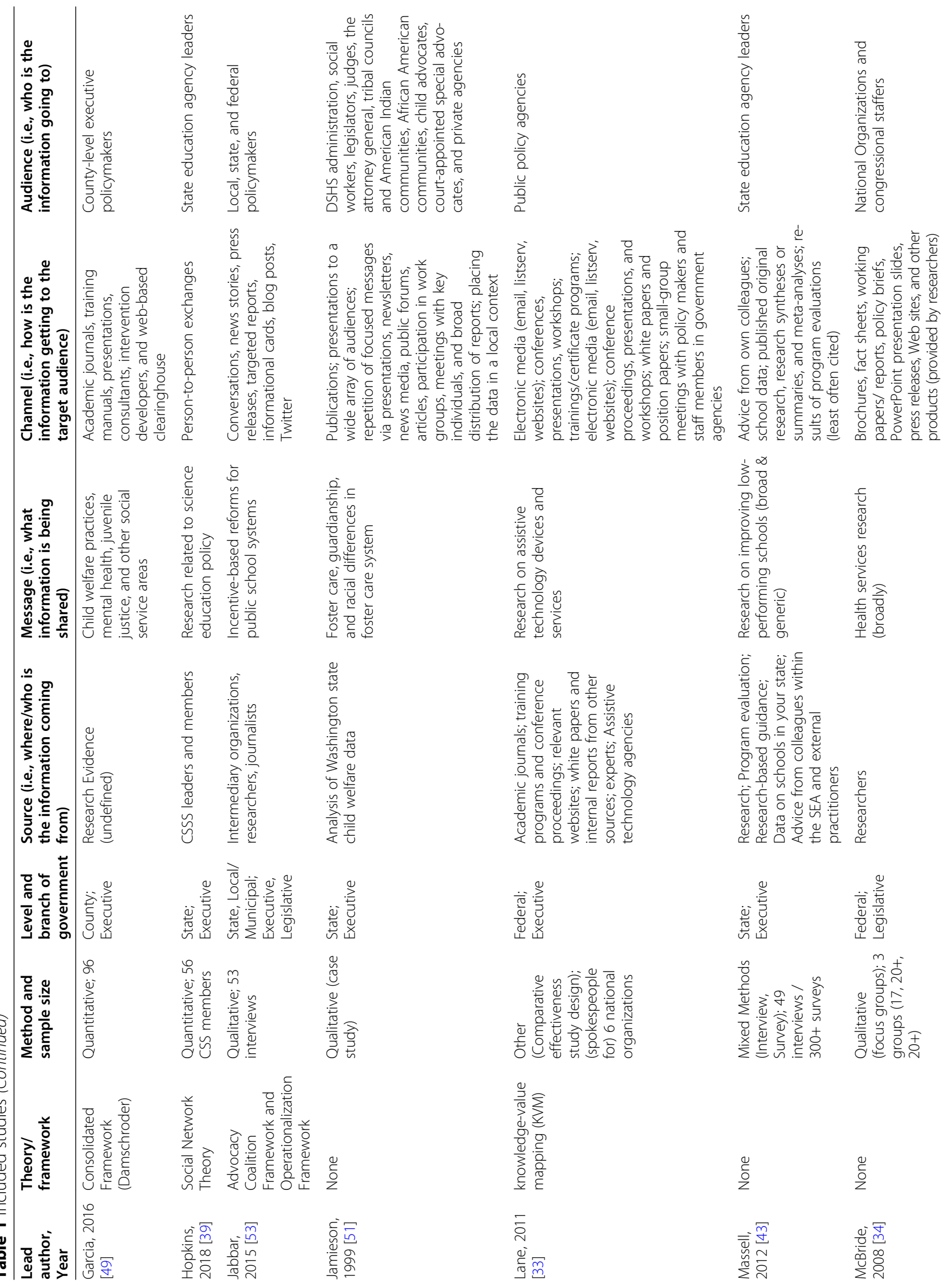




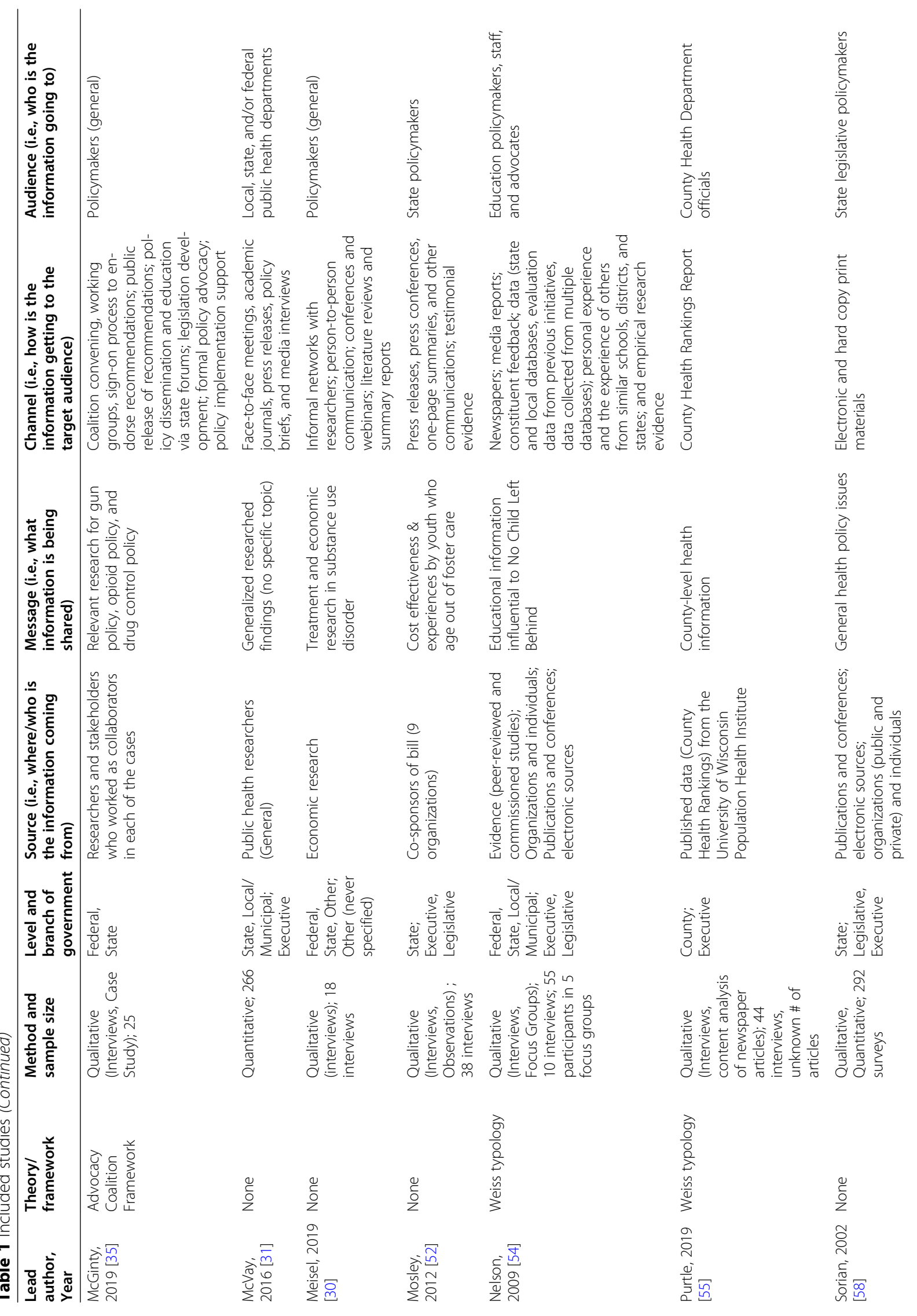




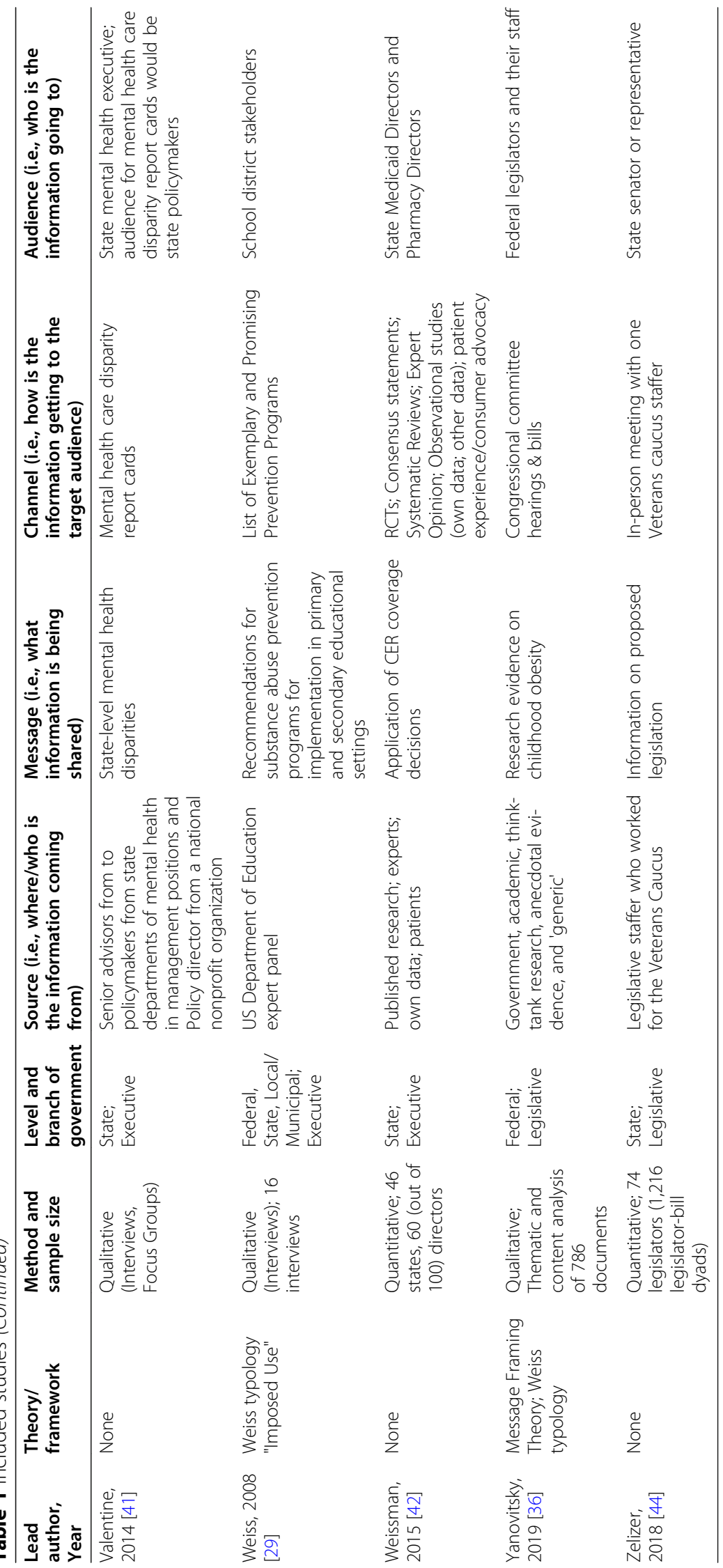


government. Included studies focused on the executive and legislative branches with no studies examining the judicial branch.

We examined dissemination based on geographic regions and/or political boundaries (i.e., regions or states). Sixteen of the 27 studies (about 59\%) used national samples or multiple states and did not provide geographic-specific results [27-42]. Two studies (about 7\%) did not specific the geographic region or state in which the study took place [43, 44]. Of the remaining studies, four examined policymaking in the Northeastern United States [45-48], four in the Western US [49-52], and one in the South [53]. The geographic regional groups used similar channels to disseminate evidence to policymakers including publications and presentations.

We also analyzed whether dissemination at different levels of government (i.e., local, state, and federal) used unique channels. Six of included studies (about 22\%) examined multiple levels of government and did not separate results based on specific levels of government [27$31,53]$. One study did not specifically identify the level of government used [46]. While there is considerable overlap in dissemination channels used at each level of government, there are some unique characteristics.

Five studies (about 18.5\%) examined dissemination at the federal level [32-36]. At the federal level, dissemination channels tended to be more formal such as congressional committee hearings [36] and legislative development [35]. Twelve studies (about 44\%) evaluated dissemination at the state level [38-44, 47, 48, 50-52]. State level dissemination heavily relied on printed materials including from mental health care disparity report cards [41], policy briefs [38], and effectiveness reports [50]. Another common channel was in-person communications such as one-on-one meetings [44] and presentations to stakeholders [51]. Three studies (about 11\%) focused on local-level government. Dissemination channels at the local level had little consistency across the three studies with channels including public education [45], reports [37], and print materials [49].

Roughly half of studies were atheoretical $(n=13)$. Four studies used the Weiss Typology [29, 36, 54, 55], two studies used the operationalization framework $[45,53]$, and two studies used the advocacy coalition framework $[53,56]$.

\section{Model for dissemination of research}

We used the Model for Dissemination of Research to summarize the findings from the included studies into the themes of source, message, audience, and channel (i.e., strategies). We integrated themes from the studies into the Model (see Fig. 3).

\section{Source}

The sources of knowledge varied across studies with some studies including multiple sources of social policy information. The most common sources of knowledge included research, as in peer-reviewed literature $(n=7)$ $[30,33,38,42,43,49,54]$, researchers $(n=5)[27,31$, $32,34,56]$, and research broadly defined $(n=5)[36,39$, $47,48,55]$, the government $(n=11)[29,36,41-44,47$, $50,54,56,57]$, and organizations $(n=7)[33,36,46,52-$ $54,56]$.

\section{Message}

The majority of studies focused on health topics ( $n=$ 12) $[29,30,33,34,38,41,42,45,47,55,56,58]$ and child and family well-being $(n=6)[27,36,46,49,52$, 57]. The remaining studies covered the topics of education $(n=4)[39,43,53,54]$, guns [56], veterans [44], and general social research $(n=3)$ [31, 32, 48]. Multiple studies offered specific recommendations for message framing, suggesting that the packaging of information is as critical as the information itself [27]. One study piloted multiple styles of policy briefs and found staffers preferred to use and share narrative or story-based briefs while legislators were more likely to use and share statistical, data-based briefs [38]. This finding was mirrored in two studies that found testimonial or descriptive evidence to be as effective as data-driven research [34, 52], particularly in the context of sympathetic populations [52]. Three studies highlighted the reliance of effective message delivery on the message's ability to capture audience interest (e.g., what the research means to the policymaker, specifically and if possible, personally) [27, 34, 41]. Finally, two studies emphasized creating a sense of urgency or even shock-value within the message in order to capture policymakers' interest $[36,57]$.

\section{Audience}

The audience included executive branch policymakers [49], administrators $(n=9)$ [27, 31, 38, 39, 41, 43, 53, $55,57]$, and staff [42]. Studies which focused on the legislative branch examined legislators $(n=12)[27,32,36$, $38,44-47,50,52,53,58]$ and staff $(n=3)[32,34,36]$. Three studies examined broadly defined policymakers $[33,54,56]$ and generalized staff [54] without indication for specific branch of government.

\section{Channel}

Included studies examined a variety of channels with many including multiple channels. Print materials was the most commonly used channel, including reports $(n=10)$ [27, 30, 33, 41, 46, 50, 53, 55, 57, 58] and policy briefs $(n=3)$ [31, 34, 38]. Researchers examined in-person meetings and communications as a channel to disseminate research $(n=9)[30,32,33$, 


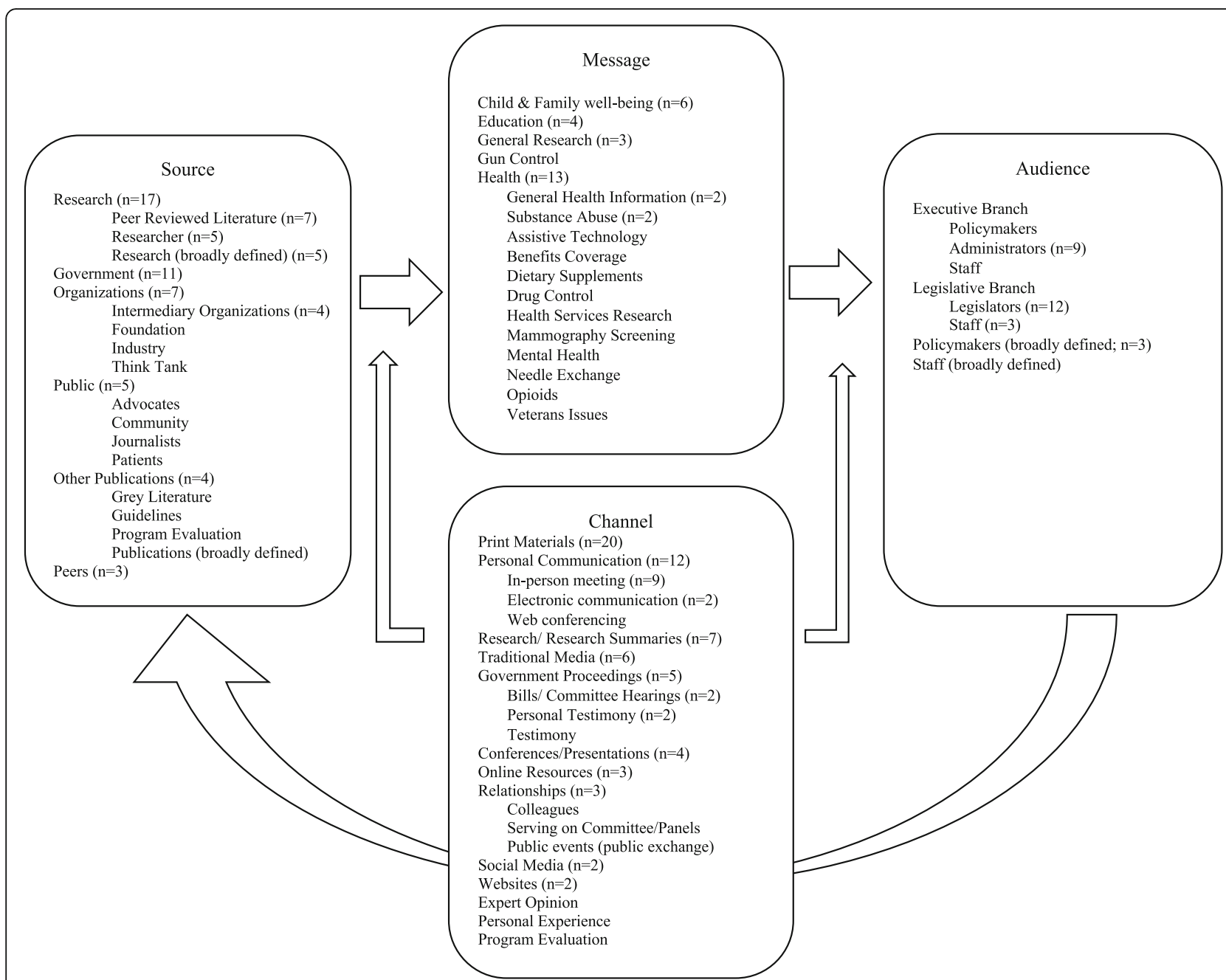

Fig. 3 A conceptual model for dissemination of research to policymakers. The populated conceptual model builds on the Model for Dissemination of Research by organizing findings from the current systematic review to build an understanding of how research is disseminated to policymakers in the United States

$39,44,48,53,56,57]$. Research and research summaries were also studied $(n=7)[30,31,42,47,49$, 52 , 54]. Both traditional $(n=6)$ [31, 33, 47, 52-54] and social media $(n=2)[47,53]$ were examined as channels to disseminate research to policymakers. Other channels include conferences and presentations $(n=4)[33,34,49,57]$, electronic communication $(n=2)$ $[27,57]$, online resources $(n=3)[34,49,58]$, and personal testimony $(n=2)[42,52]$.

\section{Effectiveness and lessons learned}

The majority of studies employed qualitative research methods (e.g., interviews, case studies, focus groups) to evaluate the impact of scientific research on domestic social policy. Our review of the literature also identified nine quantitative and mixed-methods studies [31, 32, 38, 39, $42-44,49,58]$. We identified a series of cross-cutting dissemination strategies for engaging policymakers including recommendations for and barriers to research-to-policy (see Table 2).

\section{Start early}

Four studies highlighted the importance for early and ongoing engagement with policymakers throughout the research process in order to maximize interest and applicability. Researchers are encouraged to take the initiative to contact policymakers as early as possible in the research process. Many policymakers may be interested in accessing and using research but uncertain who or how to make connections in the academic or research community [27]. Involving policymakers when designing projects and framing initial research questions increases the likelihood that key policy stakeholders will remain invested in the work by allowing their individual research interests to shine [34, 41]. Early engagement also ensures that research products (e.g., reports, policy 
Table 2 Effectiveness and lessons learned

\begin{tabular}{|c|c|c|}
\hline $\begin{array}{l}\text { Strategy for engaging } \\
\text { policymakers }\end{array}$ & Recommendations for research-policy translation & Barriers to research-policy translation \\
\hline Start early & $\begin{array}{l}\text { - Engage policymakers when planning research }[34,41] \\
\text { - Be strategic about research and audience }[29,40] \\
\text { - Take initiative to contact policymakers }[44]\end{array}$ & \\
\hline Drum up support & $\begin{array}{l}\text { - Involve a broad pool of experts [35] } \\
\text { - Cultivate broad coalition of supporters [47] }\end{array}$ & - Policymakers may appear not to value research [28] \\
\hline $\begin{array}{l}\text { Use research evidence } \\
\text { 'champions' or 'brokers' }\end{array}$ & $\begin{array}{l}\text { - Research use 'champions' engage with community } \\
\text { stakeholders and policymakers [45] } \\
\text { - Intermediary organizations connect "research supply" to } \\
\text { "research demand" [53] } \\
\text { - External brokers play a role both in connecting } \\
\text { policymakers to research and in conceptualizing and } \\
\text { developing policy }[39,43]\end{array}$ & $\begin{array}{l}\text { - Intermediary individuals or organizations may select or } \\
\text { spin research to make their point }[45,52,53] \\
\text { - Policymakers may have a list of preferred evidence } \\
\text { brokers [53] } \\
\text { - Basing policy on evidence requires identified 'best } \\
\text { evidence', which may reflect bias and favoritism [29] }\end{array}$ \\
\hline Context matters & $\begin{array}{l}\text { - Integrate research evidence into broader sociopolitical } \\
\text { context [45] } \\
\text { - Research must be locally, contextually relevant }[54,55,57] \\
\text { - Specify which government office(s) are responsible [47] }\end{array}$ & $\begin{array}{l}\text { - Federally imposed policies (e.g., education) often } \\
\text { override local expertise around context and population } \\
\text { [29] } \\
\text { - Ideology, whether personal or regional, may create a } \\
\text { barrier between researchers and policymakers [27, 41, 44, } \\
50,54-56]\end{array}$ \\
\hline $\begin{array}{l}\text { Make research products } \\
\text { timely, relevant, and } \\
\text { accessible }\end{array}$ & $\begin{array}{l}\text { - Tailor design of products to meet diverse end user needs } \\
\text { [27, 34] } \\
\text { - Present research in commonly-used formats (e.g., briefs, } \\
\text { talking points, videos) [48] } \\
\text { - Research must be timely and geared to policymakers' } \\
\text { concerns [27, 38, 42,44,52] } \\
\text { - Use clear, careful language [27] } \\
\text { - Formalize the organizational / individual process of } \\
\text { translating research to policy [32] }\end{array}$ & $\begin{array}{l}\text { - Complexity of research [56] } \\
\text { - Disconnect between the goals and language of } \\
\text { policymakers and researchers }[41,52,56] \\
\text { - Concerns about data/research evidence quality }[29,41 \text {, } \\
42]\end{array}$ \\
\hline $\begin{array}{l}\text { Know the players and the } \\
\text { process }\end{array}$ & $\begin{array}{l}\text { - Familiarize yourself with policymaking process [27, 31] } \\
\text { - Show respect for policymakers' knowledge/experiences [27] } \\
\text { - Learn about / build relationships with the target } \\
\text { policymaking audience [27, 30] } \\
\text { - Expand contact and working relationships with end users } \\
\text { [34] }\end{array}$ & $\begin{array}{l}\text { - Lack of familiarity with effective dissemination strategies } \\
\text { [31] } \\
\text { - Lack of financial and institutional support for } \\
\text { dissemination [31] }\end{array}$ \\
\hline Miscellaneous & $\begin{array}{l}\text { - Approach policy work as an educator rather than as an } \\
\text { advocate [27] }\end{array}$ & \\
\hline
\end{tabular}

briefs, factsheets) will have strategic usefulness for policymakers [30].

\section{Drum up support}

In addition to early policymaker engagement, three studies highlighted the need for researchers to garner outside support for their work, ideally involving a broad pool of experts and cultivating a broader coalition of supporters than typical academic endeavors [47]. Often, policymakers appear unwilling or uninterested in considering the application of evidence to their work $[45,53]$; when researchers can demonstrate the value and relevance of their work [58], policymakers may be more likely to engage.

\section{Use research evidence "champions" or "brokers"}

A common strategy for garnering support (as recommended above) is the use of evidence champions or brokers; these are intermediary individuals or organizations who connect research suppliers (e.g., individual researchers, academic institutions) to research demand (e.g., policymakers) [53]. These champions can broker important connections; however, researchers and policymakers alike must remember that these intermediaries are not neutral carriers of information, and may spin research in support of personal agendas $[45,52,53]$. Individual biases may also present a barrier in research-topolicy translation, as individuals or organizations are empowered to select the "best" research evidence to share with policymakers [29]. One study found that nearly half of state policymakers named professional associations as trusted sources for research information, specifically because the organization is perceived not to have a stake in the final policy outcome [58].

Two studies specifically addressed the role of intermediary organizations or brokers in the translation of research evidence to policy. Hopkins et al. [39] explored the exchange of research evidence among state education agency (SEA) leaders, while Massell et al. [43] examined more broadly the origins of research evidence use in three SEAs. Both studies found that external brokers played a role in connecting SEA policymakers to 
relevant research, as well as in the conceptualization and development of policy.

\section{Focus on context}

Multiple studies stressed the importance of research evidence being contextually relevant to the specific policy audience [29, 54, 55, 57]. For some policymakers, the needs and interests of local constituents will drive the use of research and the specifics of the policy agenda; for others, discussions that integrate research evidence into the broader sociopolitical context will be more effective [45]. For state- and local-level policymakers, policies may be most effective when based on the evidencebased understanding of local stakeholders, rather than imposed from the federal level without local contextual details [29].

Ideology of external advisors and brokers (as discussed above) and policymakers' own personal beliefs and experiences [54] and the prevailing political ideology of a particular geographic region [55] are critical components of context. Ideological beliefs, often deeply held and personal, may create a barrier between researchers and policymakers [41], though differentiating ideology from other factors that affect individual position-taking is difficult in most situations [44]. McGinty et al. [56] suggest that in polarized contexts involving strong ideological beliefs, research may add legitimacy to a particular viewpoint, though as with brokers, that research is likely to be carefully curated to support the desired message. Purtle et al. [55] concur, reporting that some county health officials were wary of the potential to spin research findings to make a case for certain programs over others and noted the need to avoid the challenge of distorting evidence. Two studies recommend positional neutrality as a researcher's best approach to handling potential ideological differences, suggesting that presenting research findings as simple fact, rather than making specific recommendations for action, may help avoid conflict and also help researchers gain credibility across the ideological spectrum $[27,50]$.

\section{Make research products timely, relevant, and accessible}

As with all research endeavors, timeliness and relevance are paramount. However, the typical timeline for academic research (years) is often too long for policymakers whose window for championing a policy action is much shorter (weeks or months) [27, 52]. A frequently reported barrier in research-to-policy translation is the complexity of research and concerns about the quality of research evidence $[29,41,56]$; one strategy for combating this concern is the use of clear, careful language [27], and tailored, audience-specific products that meet the needs of a diverse population of end users [27, 34, 58]. Research that is presented in commonly used, accessible formats (e.g., briefs, factsheets, videos) [48] may also be more effective, though one study found that use of these formats was dependent on job type, with legislators and staffers preferring different formats [58].

Multiple studies engaged with policymakers in an effort to determine how they receive research evidence and what strategies or formats are most desirable or effective [38]. After piloting four different styles of policy briefs (on the same research topic) with state-level policymakers, Brownson et al. [38] found that while all styles of brief were considered understandable and credible, opinions on the usefulness of the brief varied by the style of the brief and by the level of policymaker (e.g., legislative staff, legislators, and executive branch administrators). These findings suggest that targeted, audiencespecific research evidence materials may be more likely to be used by policymakers than generic research evidence. One study explored the usefulness of electronic vs. printed research material and again found differences by type of policymaker-legislators were more likely to read hard copy printed material, while staffers gave higher ratings to online content. Not surprisingly, the age of the policymaker also played a role in the choice to access electronic or printed material, with younger policymakers much more likely to read electronic copy than were their older peers [58].

A study on state policymakers' perceptions of comparative effectiveness research (CER) found that the most useful research is that which is consistent and specific to the needs of the policymakers [42]. The same study identified related barriers to the use of CER in policy decision-making, citing a lack of relevant high quality or conclusive research [42].

Finally, two studies described pilot projects focused on the delivery of research evidence directly to policymakers. The first cultivated researchers' capacity to accelerate the translation of research evidence into useable knowledge for policymakers through a rapid response researcher network [32]. This model was shown to be effective for both researchers (in mobilizing) and policymakers (in eliciting requests for research evidence to bolster a policy conversation or debate) [32]. The second implementation study reported on a field experiment in which state legislators randomly received relevant research about pending policy proposals [44]. Findings from this study suggest that having relevant research information increases policymakers' co-sponsorship of proposals by $60 \%$ and highlights the importance of research access in the policy process [44].

\section{Know the players and the process}

Policymakers are as much experts in their arena as researchers are in their academic fields. In order to build lasting working relationships with a target policymaking 
audience and maximize the relevance of research products for policy work, researchers must first understand the policy process $[27,30,34]$. One study examined the role of researchers themselves in disseminating findings to policymakers and identified individual- and organizational-level facilitators and barriers to the process [31]. Researchers' familiarity with the policy process, the relevance of policy dissemination to individual programs of research, and the expectation of dissemination (from higher institutional or funding bodies) facilitated the research-to-policy exchange, while lack of familiarity with effective dissemination strategies and lack of financial and institutional support for dissemination emerged as primary barriers in the research-to-policy exchange [31].

\section{Discussion}

Public policy, whether legislative, executive, or judicial, affects all areas of daily life in both obvious and subtle ways. The policy process (i.e., the steps from an idea to policy enactment) does not exist in a vacuum; it is influenced by many factors, including public opinion $[59,60]$, special interest groups [61], personal narratives [62], expressed needs of constituents [1], the media [63-65], and corporations $[66,67]$. Research may also play a role in shaping policy and has the potential to add objectivity and evidence to these other forces $[1,2,68]$. The current study synthesizes existing knowledge to understand dissemination strategies of social policy research to policymakers in the United States.

Many channels exist to disseminate evidence to policymakers, with the most common being print materials (i.e., reports and policy briefs). This finding is surprising in our current digital age, as print materials are necessarily time-bound and rapidly evolving technology has created more channels (e.g., social media, videos) which may be preferred by policymakers. This shift creates an opportunity to optimize the content of print materials to disseminate in new mediums; it also offers a chance for authors to improve the accessibility of their work for broader audiences (e.g., via more visual presentation formats) $[15,69-71]$.

Our review found strategies to increase effectiveness of research dissemination to policymakers includes starting early, drumming-up support, using champions and brokers, understanding the context, ensuring timeliness, relevance, and accessibility of research products, and knowing the players and the process. These themes align with existing knowledge about policymaker preferences including face-to-face engagement [72, 73], contextual considerations (e.g., timeliness and budget) [2, 72], and existing barriers and facilitators to research evidence use $[4,5]$. Our study adds to what we already know about policymakers' desire for research evidence and their varying preferences as to the context and form of that knowledge [2, 72, 74] and supports existing efforts to bridge the gap between researchers and policymakers.

Many of the barriers and facilitators to research dissemination that we identified in this review mirror those cited by policymakers as barriers and facilitators to evidence use; this overlap reasonably suggests that efforts to expand research dissemination may improve the other. Particularly relevant lessons from the evidence use literature that also emerged from our review include emphasis on the benefit of building personal relationships between researchers and policymakers [5, 75, 76], narrowing the perceived gap between the two groups $[77,78]$, and changing the culture of decision making to increase appreciation for the value of research in policy development [5, 75-77]. Considering the multiple pathways through which research evidence is used in policy, from providing direct evidence of a program's effectiveness to informing or orienting policy makers about relevant issues [23], these shared lessons around barriers and facilitators may better inform researchers, policymakers, and staff as to best practices for future communication and collaboration.

Our findings also highlight several unique elements of the US policy landscape, wherein significant power is reserved from the federal-level and afforded to state-level government. In some states, this power is further distributed to county and local governments. This system creates major variation across the country in both policy decisions and in resource availability for social policy implementation. Despite our relatively unique government structure, however, many of the effective strategies for dissemination we identified mirror strategies found in other countries $[79,80]$.

Studies that focused on a specific level of government had some unique characteristics such as formality and reliance on print materials. For example, federal dissemination relied more heavily on formal legislative testimony while state level material relied on written policy materials (e.g., policy briefs, report cards). However, these results are limited by small sample sizes and limited evidence about effectiveness.

A wide range of contextual variables may influence policy dissemination in the US at different levels of government. In the federal legislative context alone, multiple committees and subcommittees of both the U.S. House of Representatives and the U.S. Senate may exercise some control over programs and policies related to a single social policy issue (e.g., child and family services) [81]. At the federal level, the Congressional Research Service (CRS) provides non-partisan research support to legislators in multiple formats including reports on major policy issues, expert testimony, and responses to individual inquiries; the Domestic Social Policy Division offers Congress interdisciplinary research and analysis 
on social policy issues [82]. While there may be fewer decision-makers for each issue on the state level, policymaking is further complicated by the extensive rules and reporting requirements attached to state use of federal funding as well as competing priorities or needs at the local level within each state [83, 84]. Another dissemination influence may include geographic proximity; for example, geographical proximity may increase the likelihood of university-industry partnerships [85].

Infrastructure differences may also represent important differences between the US social policy context and that of other developed nations. Each country has a distinct and perhaps unique policy context given available resources, political rules and regulations, and priorities. While models for infrastructure and dissemination interventions may be shared across policy contexts, it may be difficult to directly compare dissemination strategies in one country with dissemination strategies in another country.

Several examples across western countries contribute to a stronger nexus between research evidence and the policy-making process. In the United States, the Wisconsin Family Impact Seminars (www.wisfamilyimpact.org) are an example of long-standing initiatives that provide the opportunity for researchers and policymakers to come together to discuss unbiased policy-relevant evidence [86]. As exemplified by Friese and Bogenschneider [27], these forums continue to be perceived as objective, relevant, and useful by policymakers and have succeeded at bringing attention to social policy [86]. Researchers and policymakers in Canada have sought to bridge the research-to-policy gap. For example, the Canadian Foundation for Healthcare Improvement (formerly the Canadian Health Services Research Foundation), funded by the Canadian federal government, brings together researchers and policymakers early and throughout the research development process to discuss, prioritize, and evaluate opportunities for research and dissemination [79]. In the UK, infrastructure at the national level includes the National Institute for Health Research Policy Research Programme, which funds health research with the explicit goal of informing national policy decisions in health and social care [87]. These efforts include open calls for research proposals as well as 15 dedicated Policy Research Units located at leading academic institutions around the country. Another resource is the EPPI-Centre at University College London, which provides policymakers support for finding and using research to inform policy decisions through its Research Advisory Service. This allows researchers to work alongside policymakers to reach their goals in addressing educational needs with evidence-informed policy [80].

\section{Limitations}

The current study has several limitations-these illustrate opportunities for future research. First, we attempted to cast a wide net when searching for studies which examined the influence of research on social policy by including a broad search of the peer-reviewed literature, think tanks, and content experts. However, it is possible we missed some studies which examine how research influences policy. Second, we provide a rationale for focusing on US studies and that our findings may not be generalizable to other countries. Third, we were unable to assess the risk of bias for individual studies as current standards note difficulties in assessing quality and bias in qualitative research [88]. Fourth, many studies examined multiple channels or strategies for how research influences policy, so the parsing of singular strategies (e.g., policy brief, in-person meeting) as an effective approach should be interpreted with caution. Additional investigation is needed to explore and test causal pathways in how these channels can best influence social policy. Fifth, the majority of studies did not use any theory or framework as a foundation or guide for exploration. This gap may indicate a space to use frameworks such as the Model for Dissemination of Research to guide future research. Finally, the dearth of mixed-methods studies that systematically evaluate the impact of research evidence on domestic social policy (this review identified only 3) presents an opportunity for future work in this field to integrate quantitative and qualitative methodologies.

One significant challenge to increasing the rigor in dissemination research studies is the difficulty in choosing and then measuring an outcome. Many of the studies included in this review are either case studies or descriptive, making it difficult to determine what, if any, impact the given research had on policy. Bogenschneider and Corbett discuss this at length as one of the primary challenges to furthering this research [72], imploring researchers not to focus solely on the outcome of whether or not a piece or legislation passes but rather to examine whether research influenced one of the proposed policy options [72]. However, this information can be difficult both to operationalize and to collect. That said, some researchers have already begun to think beyond the passage of legislation, as evidenced by Zelizer [44] who examined bill co-sponsorship rather than passage. A recent review of health policy implementation measurement found that validated quantitative measures are underutilized and recommends further development and testing of such measures [89]. Difficulties in identifying robust outcomes and high-quality scales to operationalize them present opportunities for additional exploration in this area.

Dissemination and implementation are often described together; not surprisingly, is overlap in effective 
strategies for each. The current review identified six dissemination strategies and described their reported effectiveness, while the Expert Recommendations for Implementing Change (ERIC) Project identified 73 implementation strategies [90]. One such similarity is obvious: the dissemination strategy of using champions and brokers mirrors the ERIC implementation strategy of identifying and preparing champions. The difference between the number of implementation strategies and dissemination strategies is striking and highlights the gap in research. Future work should further explore the degree to which dissemination strategies and implementation strategies either overlap or are distinct.

Finally, the dissemination of research to policymakers may raise certain ethical issues. It is imperative for researchers to critically assess when and how to disseminate research findings to policymakers, keeping in mind that promoting a specific policy agenda may result in a perceived or real loss of objectivity [91]. Syntheses of policy-relevant evidence can be useful, particularly when researchers work in partnership with non-governmental organizations to inform the policy process.

\section{Conclusions}

We summarize strategies and illuminate potential barriers to the research-to-policy dissemination process. Key findings are drawn from multiple disciplines and suggest that lessons learned may cut across both research topics and levels of government. The most frequently referenced channel for dissemination to policymakers was print materials, with personal communication (including both in-person and electronic meetings and individual communications) a close second. Corresponding strategies for effective dissemination to policymakers included starting early, drumming-up support, using champions and brokers, understanding the context, ensuring timeliness, relevance, and accessibility of research products, and knowing the players and the process. A shared feature of these strategies is the distillation of complex research findings into accessible pieces of relevant information that can then be delivered via multiple avenues.

Interdisciplinary collaboration is a common practice in scientific research [92]. Our findings provide leads on how to more effectively to engage with policymakers, leading to a greater likelihood of translating research evidence into policy action. Engaging policymakers early as contributing members of the research team, maintaining communication during the research process, and presenting relevant findings in a clear, concise manner may empower both researchers and policymakers to further apply scientific evidence to improve social policy in the United States.

\section{Supplementary information}

Supplementary information accompanies this paper at https://doi.org/10. 1186/s13012-020-01046-3.

Additional File 1. PRISMA Checklist.

Additional File 2. Search Strategy.

Additional File 3. Data Abstraction Form.

\begin{abstract}
Abbreviations
US: United States; PRISMA-P: Preferred Reporting Items for Systematic Reviews and Meta-Analyses; CER: Comparative Effectiveness Research; ERIC: Expert Recommendations for Implementing Change
\end{abstract}

\section{Acknowledgements}

None.

\section{Disclaimer}

The views expressed herein are those of the authors and do not reflect those of the Department of Veterans Affairs, the Centers for Disease Control and Prevention, or the National Institutes of Health.

\section{Authors' contributions}

Review methodology: LEA, DAQ, RCB; eligibility criteria: LEA, DAQ, RCB; search strings and terms: LEA, DAQ; abstract screening: LEA, DAQ; full text screening: LEA, DAQ; pilot extraction: LEA, DAQ; data extraction: LEA, DAQ; data aggregation: LEA, DAQ; writing: LEA, DAQ; editing: LEA, DAQ, RCB. The author(s) read and approved the final manuscript.

\section{Funding}

LEA is supported by a pre-doctoral Clinical and Translational Science Fellowship (NIH TL1 TR001858 (PI: Kraemer)). DAQ is supported by a postdoctoral fellowship through the Department of Veterans Affairs (VA) Office of Academic Affiliations and the Center for Health Equity Research and Promotion at the VA Pittsburgh Healthcare System. RCB is supported by the National Cancer Institute (P50CA244431) the Centers for Disease Control and Prevention (U48DP006395). The funding entities had no role in the development, data collection, analysis, reporting, or publication of this work. Article processing charges for this article were fully paid by the University Library System, University of Pittsburgh.

Availability of data and materials

Raw search results, citations, and abstracts available upon request.

Ethics approval and consent to participate

Not applicable.

Consent for publication

Not applicable.

\section{Competing interests}

The authors declare they have no conflicting interests.

\section{Author details}

${ }^{1}$ University of Pittsburgh School of Social Work, 2117 Cathedral of Learning, 4200 Fifth Avenue, Pittsburgh, PA 15260, USA. ${ }^{2}$ Center for Health Equity Research and Promotion (CHERP), VA Pittsburgh Healthcare System, University Drive C, Building 30, Pittsburgh, PA 15240, USA. ${ }^{3}$ Prevention Research Center, Brown School, Washington University in St. Louis, One Brookings Drive, Campus Box 1196, St. Louis, MO 63130, USA. ${ }^{4}$ Department of Surgery, Division of Public Health Sciences, and Alvin J. Siteman Cancer Center, Washington University School of Medicine, 660 South Euclid Avenue, Saint Louis, MO 63110, USA. 
Received: 18 May 2020 Accepted: 14 September 2020 Published online: 15 October 2020

\section{References}

1. Dodson EA, Geary NA, Brownson RC. State legislators' sources and use of information: bridging the gap between research and policy. Health Educ Res. 2015;30:840-8.

2. Purtle J, Dodson EA, Nelson K, Meisel ZF, Brownson RC. Legislators' sources of behavioral Health research and preferences for dissemination: variations by political party. Psychiatr Serv. 2018; appi.ps.201800153.

3. Purtle J, Peters R, Brownson RC. A review of policy dissemination and implementation research funded by the National Institutes of Health, 20072014. Implement Sci. 2016;11.

4. Oliver K, Innvar S, Lorenc T, Woodman J, Thomas J. A systematic review of barriers to and facilitators of the use of evidence by policymakers. BMC Health Serv Res. 2014;14:2.

5. Innvær S, Vist G, Trommald M, Oxman A. Health policy-makers' perceptions of their use of evidence: a systematic review. J Health Serv Res Policy. 2002;7:239-44.

6. El-Jardali F, Lavis JN, Ataya N, Jamal D. Use of health systems and policy research evidence in the health policymaking in eastern Mediterranean countries: views and practices of researchers. Implement Sci IS. 2012;7:2.

7. Campbell DM, Redman S, Rychentnik L, Cooke M, Zwi AB, Jorm L. Increasing the use of evidence in health policy: practice and views of policy makers and researchers. Aust N Z Health Policy CSIRO. 2009;6.

8. Dean H. Social Policy. Cambridge: Polity; 2012.

9. Gilbert N, Terrell P. Dimensions of social welfare policy. 8th ed. Boston: Pearson; 2012.

10. Marshall TH. Citizenship and social class. Cambridge; 1950.

11. Shannon CE. A mathematical theory of communication. Bell Syst Tech J. 1948;27:379-423.

12. Weaver W, Shannon CE. The mathematical theory of communication. Champaign: University of Illinois Press; 1963.

13. McGuire W. The nature of attitudes and attitude change. Vol. 3. Reading: Addison-Wesley Pub. Co; 1969.

14. McGuire WJ, Rice R, Atkin C. Input and output variables currently promising for constructing persuasive communications. Public Commun Campaigns. 2001;3:22-48.

15. Brownson RC, Eyler AA, Harris JK, Moore JB, Tabak RG. Getting the Word Out: New Approaches for Disseminating Public Health Science. J Public Health Manag Pract JPHMP. 2018;24:102-11.

16. Rogers EM. Diffusion of Innovations, 5th Edition: Simon and Schuster; 2003.

17. Kotler P, Zaltman G. Social marketing: an approach to planned social change. J Mark. 1971;35:3-12.

18. Best A, Holmes B. Systems thinking, knowledge and action: towards better models and methods. Evid Policy J Res Debate Pract Policy Press. 2010;6:145-59.

19. Moher D, Shamseer L, Clarke M, Ghersi D, Liberati A, Petticrew M, et al. Preferred reporting items for systematic review and meta-analysis protocols (PRISMA-P) 2015 statement. Syst Rev. 2015:4:1.

20. Shamseer L, Moher D, Clarke M, Ghersi D, Liberati A, Petticrew M, et al. Preferred reporting items for systematic review and meta-analysis protocols (PRISMA-P) 2015: elaboration and explanation. BMJ. 2015;349:97647.

21. Political party - Two-party systems. Encycl. Br. 2020 [cited 2020 Aug 10]. Available from: https://www.britannica.com/topic/political-party.

22. Mahoney C. Why lobbying in America is different [Internet]. POLITICO. 2009 [cited 2020 Aug 10]. Available from: https://www.politico.eu/article/whylobbying-in-america-is-different/.

23. Tseng V, Coburn C. Using evidence in the US. What Works Evid-Inf Policy Pract. Bristol: Policy Press; 2019. p. 351-68.

24. Stern MJ. Social Policy: History (1950-1980). Encycl Soc Work. 2013; [cited 2020 Apr 17]. Available from: https://oxfordre.com/socialwork/view/10.1093/ acrefore/9780199975839.001.0001/acrefore-9780199975839-e-610.

25. Ashcraft LE, Asato M, Houtrow AJ, Kavalieratos D, Miller E, Ray KN. Parent empowerment in pediatric healthcare settings: A systematic review of observational studies. Patient Patient Centered Outcomes Res. 2019:12:199-212.

26. Jacobs LA, Ashcraft LE, Sewall CJR, Folb BL, Mair C. Ecologies of juvenile reoffending: a systematic review of risk factors. J Crim Just. 2020;66:101638.

27. Friese B, Bogenschneider K. The voice of experience: how social scientists communicate family research to policymakers. Fam Relat. 2009;58:229-43.

28. Nelson JW, Scammell MK, Altman RG, Webster TF, Ozonoff DM. A new spin on research translation: the Boston Consensus Conference on Human Biomonitoring. Environ Health Perspect. 2009;117:495-9.
29. Weiss CH, Murphy-Graham E, Petrosino A, Gandhi AG. The fairy godmother-nd her warts. Am J Eval. 2008;29:29-47.

30. Meisel ZF, Mitchell J, Polsky D, Boualam N, McGeoch E, Weiner J, et al. Strengthening partnerships between substance use researchers and policy makers to take advantage of a window of opportunity. Subst Abuse Treat Prev Policy. 2019;14:12

31. McVay AB, Stamatakis KA, Jacobs JA, Tabak RG, Brownson RC. The role of researchers in disseminating evidence to public health practice settings: a cross-sectional study. Health Res Policy Syst. 2016;14:1-9.

32. Crowley M, Scott JTB, Fishbein D. Translating prevention research for evidence-based policymaking: results from the research-to-policy collaboration pilot. Prev Sci. 2018;19:260-70.

33. Lane JP, Rogers JD. Engaging national organizations for knowledge translation: Comparative case studies in knowledge value mapping. Implement Sci. 2011;6.

34. McBride T, Coburn A, MacKinney C, Mueller K, Slifkin R, Wakefield M. Bridging health research and policy: effective dissemination strategies. J Public Health Manag Pract. 2008;14:150-4.

35. McGinty EE, Siddiqi S, Linden S, Horwitz J, Frattaroli S. Improving the use of evidence in public health policy development, enactment and implementation: a multiple-case study. Health Educ Res. 2019:34:129-44.

36. Yanovitzky I, Weber M. Analysing use of evidence in public policymaking processes: a theory-grounded content analysis methodology. 2019 [cited 2019 May 8]. Available from: https://www.ingentaconnect.com/content/tpp/ ep/pre-prints/content-ppevidpold1700095.

37. Purtle J, Lê-Scherban F, Wang XI, Shattuck PT, Proctor EK, Brownson RC State Legislators' Support for Behavioral Health Parity Laws: The Influence of Mutable and Fixed Factors at Multiple Levels. Milbank Q. 2019:97:1200-32.

38. Brownson RC, Dodson EA, Stamatakis KA, Casey CM, Elliott MB, Luke DA, et al. Communicating evidence-based information on cancer prevention to state-level policy makers. J Natl Cancer Inst. 2011;103:306-16.

39. Hopkins M, Wiley KE, Penuel WR, Farrell CC. Brokering research in science education policy implementation: the case of a professional association. Evid Policy. 2018;14:459-76.

40. Sorian $\mathrm{R}$, Baugh T. Power of information: closing the gap between research and policy. Health Aff (Millwood). 2002;21:264-73.

41. Valentine A, DeAngelo D, Alegria M, Cook BL. Translating disparities research to policy: a qualitative study of state mental health policymakers' perceptions of mental health care disparities report cards. Psychol Serv. 2014;11:377-87.

42. Weissman JS, Westrich K, Hargraves JL, Pearson SD, Dubois R, Emond S, et al. Translating comparative effectiveness research into Medicaid payment policy: views from medical and pharmacy directors. J Comp Eff Res. 2015:4:79-88.

43. Massell D, Goertz ME, Barnes CA. State education agencies' acquisition and use of research knowledge for school improvement. Peabody J Educ. 2012:87:609-26.

44. Zelizer A. How Responsive Are Legislators to Policy Information? Evidence from a field experiment in a state legislature. Legis Stud Q. 2018;43:595-618.

45. Allen ST, Ruiz MS, O'Rourke A. The evidence does not speak for itself: The role of research evidence in shaping policy change for the implementation of publicly funded syringe exchange programs in three US cities. Int J Drug Policy. 2015;26:688-95.

46. Brim OG Jr, Dustan J, Brim OG Jr. Translating research into policy for children: the private foundation experience. Am Psychol. 1983:38:85-90.

47. Austin SB, Yu K, Tran A, Mayer B. Research-to-policy translation for prevention of disordered weight and shape control behaviors: a case example targeting dietary supplements sold for weight loss and muscle building. Eat Behav. 2017;25:9-14.

48. Bumbarger B, Campbell E. A state agency-university partnership for translational research and the dissemination of evidence-based prevention and intervention. Adm Policy Ment Health Ment Health Serv Res. 2012;39:268-77.

49. Garcia AR, Kim M, Palinkas LA, Snowden L, Landsverk J. Socio-contextual determinants of research evidence use in public-youth systems of care. Adm Policy Ment Health Ment Health Serv Res. 2016;43:569-78.

50. Coffman JM, Hong M-K, Aubry WM, Luft HS, Yelin E. Translating medical effectiveness research into policy: lessons from the California health benefits review program. Milbank Q. 2009;87:863-902.

51. Jamieson M, Bodonyi JM. Data-driven child welfare policy and practice in the next century. Child Welfare. 1999:78:15-30.

52. Mosley JE, Courtney ME. Partnership and the politics of care: advocates' role in passing and implementing California's law to extend foster care: Chapin Hall Center for Children; 2012. 
53. Jabbar H, Goel La Londe P, Debray E, Scott J, Lubienski C. How Policymakers Define 'Evidence': The Politics of Research Use in New Orleans. Policy Futur Educ. 2015;12:286-303.

54. Nelson SR, Leffler JC, Hansen BA. Toward a research agenda for understanding and improving the use of research evidence. Northwest Reg Educ Lab NWREL. 2009.

55. Purtle J, Peters R, Kolker J, Diez Roux AV. Uses of population health rankings in local policy contexts: A multisite case study. Med Care Res Rev. 2019;76: 478-96.

56. McGinty B, Siddiqi S, Linden S. Academic research-policy translation strategies to improve the use of evidence in health policy development, enactment and implementation: a 3-part embedded case study. Implement Sci. 2018;13.

57. Jamieson M, Bodonyi JM. Data-driven child welfare policy and practice in the next century. Fam Foster Care Century. 2001;13.

58. Sorian R, Baugh T. Power of information: closing the gap between research and policy. Health Aff (Millwood). Health Aff. 2002;21:264-73.

59. Burstein $P$. The impact of public opinion on public policy: a review and an agenda. Polit Res Q. 2003:56:29-40.

60. Pacheco J, Maltby E. The role of public opinion-does it influence the diffusion of ACA decisions? J Health Polit Policy Law. 2017:42:309-40.

61. Wolton S. Lobbying, Inside and Out: How special interest groups influence policy choices. Rochester, NY: Social Science Research Network; 2017 Mar. Report No.: ID 2190685. Available from: https:/papers.ssrn.com/abstract=2190685.

62. Stamatakis KA, McBride TD, Brownson RC. Communicating prevention messages to policy makers: the role of stories in promoting physical activity. J Phys Act Health. 2010;7:S99-107.

63. Otten AL. The influence of the mass media on health policy. Health Aff (Millwood). Health Aff. 1992;11:111-8.

64. Robinson P. Theorizing the influence of media on world politics: models of media influence on foreign policy. Eur J Commun. 2001;16:523-44.

65. Shanahan EA, McBeth MK, Hathaway PL. Narrative policy framework: the influence of media policy narratives on public opinion. Polit Policy. 2011;39: 373-400.

66. Salamon LM, Siegfried JJ. Economic power and political influence: the impact of industry structure on public policy. Am Polit Sci Rev. 1977;71: 1026-43.

67. Shelley D, Ogedegbe G, Elbel B. Same strategy different industry: corporate influence on public policy. Am J Public Health. 2014;104:e9-11.

68. Hird JA. Policy Analysis for What? The effectiveness of nonpartisan policy research organizations. Policy Stud J. 2005;33:83-105.

69. Trost MJ, Webber EC, Wilson KM. Getting the word out: disseminating scholarly work in the technology age. Acad Pediatr. 2017;17:223-4.

70. Kapp JM, Hensel B, Schnoring KT. Is Twitter a forum for disseminating research to health policy makers? Ann Epidemiol. 2015;25:883-7.

71. Dodson EA, Eyler AA, Chalifour S, Wintrode CG. A review of obesity-themed policy briefs. Am J Prev Med. 2012;43:S143-8.

72. Bogenschneider K, Corbett TJ. Evidence-based policymaking: Insights from policyminded researchers and research-minded policymakers: Routledge; 2011.

73. Mitton C, Adair CE, Mckenzie E, Patten SB, Perry BW. Knowledge transfer and exchange: review and synthesis of the literature. Milbank Q. 2007:85: 729-68.

74. Purtle J, Lê-Scherban F, Shattuck P, Proctor EK, Brownson RC. An audience research study to disseminate evidence about comprehensive state mental health parity legislation to US State policymakers: protocol. Implement Sci. 2017;12:1-13.

75. Van der Arend J. Bridging the research/policy gap: policy officials' perspectives on the barriers and facilitators to effective links between academic and policy worlds. Policy Stud. 2014;35:611-30.

76. Langer L, Tripney J, Gough DA. The science of using science: researching the use of research evidence in decision-making: UCL Institute of Education, EPPI-Centre; 2016.

77. Orton L, Lloyd-Williams F, Taylor-Robinson D, O'Flaherty M, Capewell S. The use of research evidence in public health decision making processes: systematic review. PLoS One. 2011;6:e21704

78. Hennink M, Stephenson R. Using research to inform health policy: barriers and strategies in developing countries. J Health Commun. 2005;10:163-80.

79. Lomas J. Essay: Using 'Linkage And Exchange' To move research into policy at a Canadian Foundation. Health Aff (Millwood). Health Aff. 2000;19:236-40.

80. EPPI-Centre. Research Advisory Service. 2019 [cited 2020 Aug 4]. Available from: https://eppi.ioe.ac.uk/cms/Default.aspx?tabid=3421.
81. Kerner JF, Hall KL. Research dissemination and diffusion: translation within science and society. Res Soc Work Pract. 2009:19:519-30.

82. Library of Congress. About CRS - congressional research service (Library of Congress). 2020 [cited 2020 Aug 26]. Available from: https://www.loc.gov/ crsinfo/about/.

83. Edwards C. Complexity in State Government. 2020 [cited 2020 Aug 31]. Available from: https://www.cato.org/blog/complexity-state-government.

84. Urban Institute. State and Local Expenditures [Internet]. Urban Inst. 2020 [cited 2020 Aug 25]. Available from: https://www.urban.org/policy-centers/ cross-center-initiatives/state-and-local-finance-initiative/state-and-localbackgrounders/state-and-local-expenditures.

85. D'Este P, Guy F, lammarino S. Shaping the formation of university-industry research collaborations: what type of proximity does really matter? J Econ Geogr. 2013;13:537-58

86. Owen JW, Larson AM. Researcher-policymaker partnerships: Strategies for launching and sustaining successful collaborations: Routledge; 2017.

87. National Institute for Health Research. Policy research. 2020 [cited 2020 Sep 4]. Available from: https://www.nihr.ac.uk/explore-nihr/fundingprogrammes/policy-research.htm.

88. Higgins J, Green S. Cochrane Handbook for systematic reviews of interventions. 2011 [cited 2018 Sep 20]. Available from: /handbook.

89. Allen P, Pilar M, Walsh-Baily C, Hooley C, Mazzucca S, Lewis C, et al. Quantitative measures of health policy implementation determinants and outcomes: a systematic review. Implement Sci. 2020.

90. Powell BJ, Waltz TJ, Chinman MJ, Damschroder LJ, Smith JL, Matthieu MM et al. A refined compilation of implementation strategies: results from the Expert Recommendations for Implementing Change (ERIC) project. Implement Sci. 2015;10:21.

91. Brownson RC, Hartge P, Samet JM, Ness RB. From epidemiology to policy: toward more effective practice. Ann Epidemiol. 2010;20:409.

92. Carroll L, Ali MK, Cuff P, Huffman MD, Kelly BB, Kishore SP, et al. Envisioning a transdisciplinary university. J Law Med Ethics. 2014;42:17-25.

\section{Publisher's Note}

Springer Nature remains neutral with regard to jurisdictional claims in published maps and institutional affiliations.

Ready to submit your research? Choose BMC and benefit from:

- fast, convenient online submission

- thorough peer review by experienced researchers in your field

- rapid publication on acceptance

- support for research data, including large and complex data types

- gold Open Access which fosters wider collaboration and increased citations

- maximum visibility for your research: over $100 \mathrm{M}$ website views per year

At BMC, research is always in progress.

Learn more biomedcentral.com/submissions 